\title{
Using Digital Smart Board to Overcome Higher Order Thinking Skills Learning Difficulties in Data Handling among Primary School Students
}

\author{
https://doi.org/10.3991/ijim.v12i7.9644 \\ Elizabeth Julius \\ Kebbi State University of Science and Technology Aliero, Kebbi State, Nigeria
}

\author{
Soh Hon Mun $\left.{ }^{\bowtie}\right)$, Abdul Halim Abdullah, Mahani Mokhtar, Nornazira Suhairom \\ Universiti Teknologi Malaysia, Johor Bahru, Malaysia \\ munmun1103@live.com.my
}

\begin{abstract}
Data Handling at primary school involves gathering and recording information and then presenting it in a way that is meaningful to others. It is a fundamental part of student's mathematical understanding. Initial concepts of Data Handling need to be exposed to students in the early years as these skills will be used and built upon throughout their education. Due to its importance, Data Handling is included in the curriculum at primary level in Malaysia. However results of international assessments which focused on the use of higher order thinking skills showed that Malaysian students performed poorly in Data Handling. Therefore, this study was conducted to identify students' learning difficulties in Data Handling at each level of higher order thinking skills (HOTS) namely applying, analysing, evaluating and creating. In addition, this study also investigated the use of smart board in overcoming HOTS learning difficulties in Data Handling. Numerous teachers recommend the use of smart board at primary schools since students have the opportunity to explore and learn novel concepts using the technology. Subsequently, it helps to generate dynamic learning experiences and student in school become more motivated about learning when the smart board is used during their lessons. Four experienced year five mathematics teachers and thirty year five students from a primary school were involved in the study. The students and teachers were selected based on purposive sampling. An interview protocol and rubric for cognitive domain in HOTS were used during the data collection phase. In addition, semi-structured interview sessions with the teachers and students as well as document analysis of the students' mathematics exercise sheets in Data Handling were carried out by the researcher to investigate the students' learning difficulties at each level of HOTS in Data Handling. It is hoped that the results from this study can contribute towards development of strategies, methods or programs using smart board to enhance HOTS in Data Handling among primary school students in Malaysia.
\end{abstract}

Keywords - Data Handling; learning difficulties; smart board; higher order thinking skills; primary school 


\section{Introduction}

Data Handling is an important aspect of mathematics which relates to collecting, representing and analysing data in order to solve a particular question or problem [29], [33]. It is an important subtopic of statistics which brings student out into the real world of seeing data, reflecting upon it socially or individually, and make decisions from it [39]. Several research have emphasized on the effectiveness of Data Handling in daily lives, requirement for basic Data Handling knowledge in most of the career, its instrumental role in other disciplines, as well as the main role of Data Handling in developing critical reasoning [10], [11].

Data handling is taught in Malaysian primary schools since students start their first year of schooling [24]. Students are taught to construct, organise and interpret various data from tables, charts and graphs. However, previous results showed that Malaysian students generally performed badly in data handling in two international assessments namely: Trends in International Mathematics and Science Assessment (TIMSS) and Programme for International Student Assessment (PISA).

One of the content in PISA assessment is uncertainty and data whereby students need to read, interpret and use data presented in mathematical graphical forms. Consequently, the mathematical process category involves interpreting, applying and evaluating mathematical outcomes. The item in PISA involves reasoning about the data presented, thinking mathematically about the relationship between their presentation and the data, and evaluating the result. With regard to aspects of school location and mathematics content in PISA 2012, Malaysian students in urban and rural areas performed moderately in uncertainty and data [29]. On the other hand, one of the content in TIMSS assessment is data and chance. It stresses on the fundamentals of probability and interpretation of data and students should be able to read different data displays, work with data that have been collected by others or involve themselves in simple data gathering plans. Students should be able to develop skills in identifying a range of forms of data display and representing data. From TIMSS 2003 to TIMSS 2011, the results of Malaysian students in the domains of data and chance dropped the most as compared to other TIMSS domains. The average score fell from 505 in 2003 to 429 in 2011 [39].Generally, the students did not possess HOTS in data handling.

At present, Malaysia is undergoing a dramatic transformation in the local educational system in terms of facilitating teaching and learning practices in the classroom. A result from UNESCO assessment highlights that Malaysia is among the first few countries in the world to implement a strategic ICT plan for its education system, whereby the objective is to attach the potential of ICT to increase the overall quality of education system in Malaysia [25]. Smart board was introduced by MOE in Malaysia in 2004 [23]. It is one of the more widely-used interactive technology tools in primary schools nowadays as compared to others such as laptops and document camera. Smart board promotes students learning motivation, increases their learning involvement and also assists in the enhancement of HOTS by involving students and generating their learning interest. Student commitment has been recognized as an important aspect in the learning process [3], [14], [26], [32], [35]. 
Therefore, it is crucial to identify students' learning difficulties at each level of HOTS in Data Handling and the potential of using smart board in overcoming the difficulties. Findings from the data can be used to develop strategies, methods or programs for effective learning in order to enhance HOTS in Data Handling using smart board among primary school students in Malaysia.

\section{Methodology}

This study used qualitative research approach to identify students' learning difficulties at each level of HOTS in Data Handling. It was conducted in a Malaysian public primary school. Four year five primary school mathematics teachers who possess more than twenty years of teaching experiences in a Malaysian primary school and thirty year five students were involved in the study. The selection of students in this study was based on purposive sampling. They were from different classes with average academic achievement in mathematics. The researcher was fully involved with the teachers and students during the data collection. The study used a set of interview protocol and a set of rubric for cognitive domain in HOTS. In order to test the validity of the data; individual interview sessions with open-ended questions were conducted with the mathematics teachers and students. In addition, document analysis of the students' mathematics exercise sheets in the topic of Data Handling was carried out to identify the students' learning difficulties at each level of the cognitive domain in HOTS in Data Handling. The interview questions were based on social constructivism theory [40] and active learning theory [21]. A set of rubric for cognitive domain in HOTS was used to determine the cognitive domain in HOTS during the interview. In addition, the students' mathematics exercise sheets were analysed and coded based on Anderson and Krathwohl's Revised Taxonomy. In addition, to identify the potential use of smart board in overcoming HOTS learning difficulties in Data Handling for primary school students, research papers were rifled through electronic databases such as Google Scholar, JSTOR, SAGE Journals, ScienceDirect, and Web of Science. Keywords such as smart board, interactive white boards and HOTS were used to search for correlated publications.

\section{$3 \quad$ Findings of the study}

The students' interview data highlighted that their teachers used a traditional method namely "chalk and talk" while teaching Data Handling in class. Thus, the students were passive and be in receptive mode only. Subsequently, they just listened to the teachers. In addition, teacher centered approach was used where students merely observed quietly and did exercises in their workbook individually. Thus, the teacher had full control of the classroom and its activities. Consequently, students did not have the chance to think reflectively and performed discussion with friends while learning Data Handling in class. This finding is exemplified in the excerpts from the data as listed below; $\mathrm{S}$ refers to the students:

S1: "Teachers just use the whiteboard to teach in front of the class and we just listen." 
S2: "Teachers seldom use the computer in the class while teaching."

S3: "We just learn from teacher and do drill exercises in Data Handling individually after the lesson."

S4: "We do not do reflections after lesson."

S5: "Teachers seldom let us do discussion with friends in class. We just watch teacher teach in class."

Consequently, students faced various difficulties while learning Data Handling. Majority of the students and teachers expressed similar views on students' learning difficulties at each level of the HOTS cognitive domain in Data Handling. The findings from interview and document analysis on students' learning difficulties at each level of the HOTS cognitive domain in Data Handling when the teacher only used teacher centered approach, "chalk and talk" method in the class are presented below:

\subsection{Students' learning difficulties in applying}

Applying focuses on students' ability to use new concepts or knowledge, to solve problems in new circumstances, or spontaneous use of an idea by applying acquired facts, knowledge, skills, and rules in new ways. Most primary school students failed to apply mathematical knowledge and skills while doing Data Handling tasks as they did not understand the mathematical words used in class activities. Students showed that they did not understand the terms used in Data Handling. Figure 1 shows a student's work when they solved an exercise on applying. The student did not understand the sentences which required them to find the mode and also they did not understand the term "range". The student faced difficulties in reading and understanding the questions. As a result they took a long time to get to the information required in the questions.

S6: "I do not know what the questions want? I do not understand the words used in the questions."

3. The statistic barbelow shows a student's savings within $12 \mathrm{~m}$ onths.

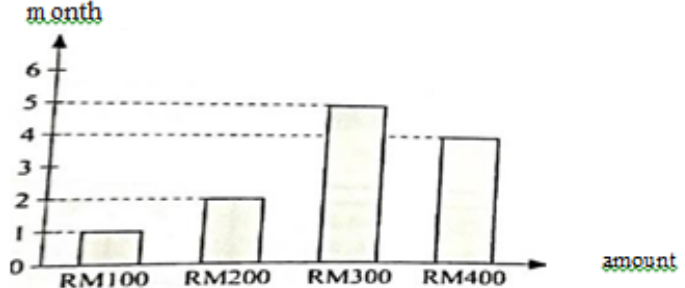

(a) What is the am ount of $m$ oney that this student earns in $m$ ost $m$ onths? Draw a tick $\sqrt{\text { in the box }}$.
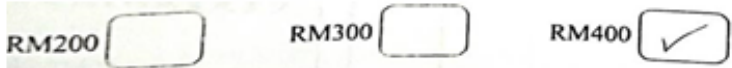

(b) Calculate the range for this set of data.

$R M 400-R M 100=R M 300$

Fig. 1. A sample of student's work on exercise sheets in applying 
In addition, Figure 2 shows an example whereby a student did not know how to solve the problems as he did not understand the term "mode". Thus, he was unable to understand the mathematical concepts in Data Handling.

S7: "I do not know what concept to use and how to answer the question?"

\begin{tabular}{|c|c|c|c|c|c|}
\hline Day & Monday & Tuesday & Wednesday & Thursday & Friday \\
\hline Savings & RM1.00 & RM1.80 & RM2.00 & RM1.50 & RM1.80 \\
\hline \multicolumn{6}{|c|}{ Table 1} \\
\hline \multicolumn{4}{|c|}{ Write out the mode of the savings. } & \multirow{2}{*}{\multicolumn{2}{|c|}{ (2 marks) }} \\
\hline \multirow{2}{*}{\multicolumn{5}{|c|}{$R M 1.00$}} & \\
\hline \multicolumn{5}{|c|}{$\begin{array}{l}R M 1.80 \\
\operatorname{SM} 2.00\end{array}$} & \\
\hline \multicolumn{6}{|c|}{$-\overrightarrow{R M I} .00+\bar{R} M 1.80+R M 2.00+R M 1.50+R M 1.80$} \\
\hline \multicolumn{2}{|c|}{$=R M 8.10$} & \multicolumn{4}{|c|}{ RM 8.10} \\
\hline
\end{tabular}

Fig. 2. A sample of student's work on exercise sheets in applying

The school teachers also pointed out that one of the main reasons for the students' inability to understand the terminology used in the questions was because of their difficulties in understanding the language. Language barrier would result in having to allocate more time to answer the questions. Thus, the students might not have sufficient time to answer all the questions and made careless mistakes. The findings were highlighted in the excerpts below, T refers to teacher.

T1: "Most of the students always confuse with the questions on Data Handling."

T2: "Students had problem to understand the question on Data Handling. They spent a lot of time to understand the problem. Students failed to collect and record data as well as constructing graphs from the data given."

Figure 3 shows another example of a student's work on mathematics exercise sheets in applying. The student had to perform some steps in order to get the answers therefore, he needed a lot of time to understand the question and get the mean. As a result, he made some careless mistakes when applying the calculation. Then, the student needed to construct a vertical pictogram. He failed to make connection to the problem, unable to draw a vertical pictogram correctly and the title and scale were also incorrect. Thus, data from the worksheet showed that the student did not have sufficient knowledge to apply the concepts in Data Handling to solve the questions. 


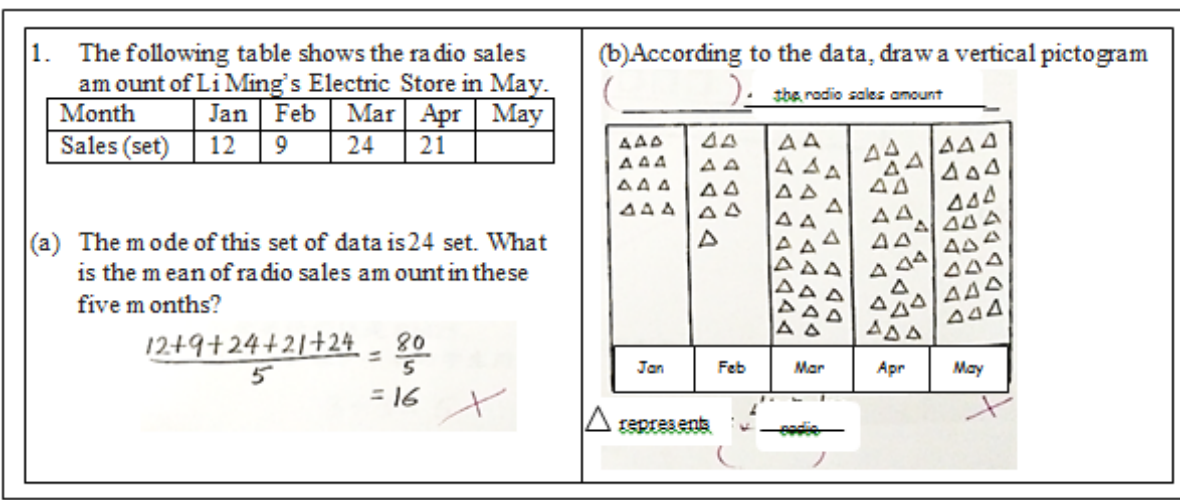

Fig. 3. An example of a student's work on mathematics exercise sheets in applying

Consequently, most primary school students were not familiar with the vocabulary used to present mathematical concepts and symbols when they have to solve problems. Thus, misinterpretation of semantics of mathematical text can often be a cause of students' failure. Language is very important for students' cognitive development because language offers the concepts for thinking and consequently a means for questioning and expressing thoughts [40]. However, primary school teachers do not use words to construct students' interpretation of experiences. Students' experiences are crucial as they shape students' language; and in the culture of schools a concept does not occur until it has been named and its meaning is shared with others [18].

\subsection{Students' learning difficulties in analysing}

Analysing emphasizes the process of examining and breaking information into small parts by identifying purposes or causes to build an organizational structure that is easily understood by students. Hence, the ability to distinguish facts from inferences is the main purpose of an analysis category. Students need an understanding of structural forms and also content of the subjects. Data showed that when primary school students understood the mathematical problems, they still could not answer the questions related to Data Handling. Excerpts from the interview are shown below:

S8: "I often make mistakes while dealing with the facts in the questions on Data Handling."

S9: "I still make mistakes in the working procedure."

Figure 4 shows a student's work on mathematics exercise sheets in analysing. Although the student understood the term "range" used in Data Handling, he made mistakes while dealing with the facts in the questions. In the worksheet, the picture of one book represented four reference books. The student failed to make connection of the problem on Data Handling. 


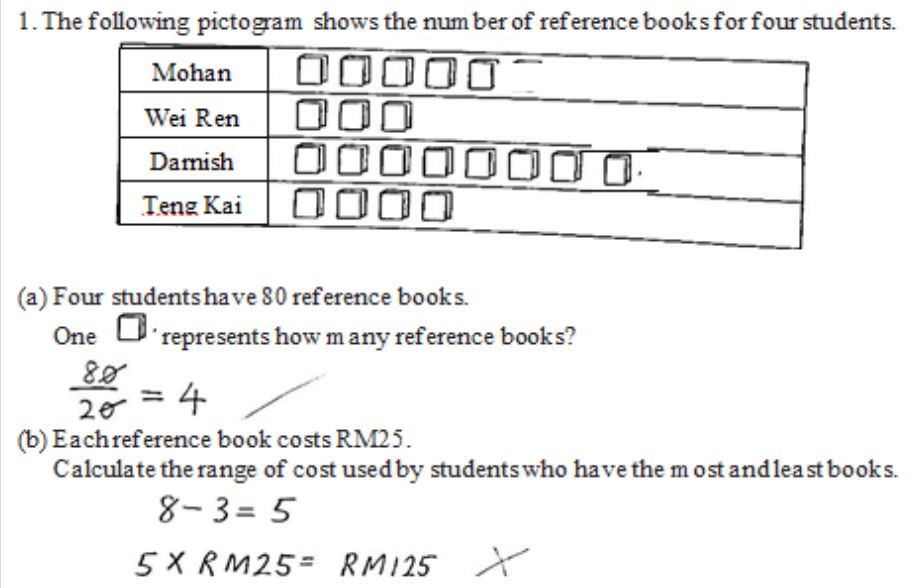

Fig. 4. A sample of student's work on mathematics exercise sheets in analysing

Next, Figure 5 shows that the student faced difficulty in identifying the concept of mean in Data Handling.

S10: "I am so confused on how to answer the problems on Data Handling."

T3 : "Students mostly do not understand which fact to use first, unsure how to make connection, which fact and formula to use."

2. The mean of 7 numbersis 135 .

(a) Find the sum of the 7 numbers above.

$$
\frac{135^{*}}{7}=19 \text { with a remainder of } 2
$$

(b) The answer from 2 (a) plus 5 num bers, the m ean of these 5 num bersis 111. Calculate the mean for this set of data.

$$
\begin{aligned}
& \frac{135+111}{5+7}=\frac{246}{12} \\
= & 20 \text { with a remainder of } 5
\end{aligned}
$$

Fig. 5. A sample of student's work on mathematics exercise sheets in analysing

In addition, the study also showed that the students faced difficulty in examining and breaking information into parts by identifying purposes or causes, making a table or graph and making connection of the problems. Figure 6 shows the student failed to make connection when he was asked to calculate a new mode, median and range in Data Handling when a new mean was given. 


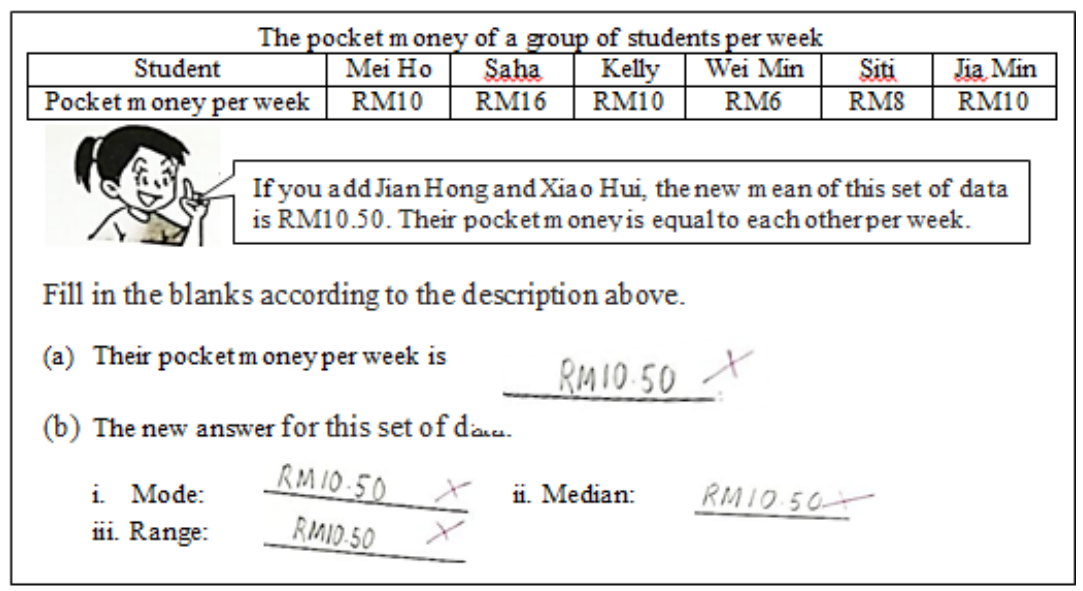

Fig. 6. A sample of student's work on mathematics exercise sheets in analysing

Thus, primary school students did not have pre-requisite knowledge on algorithms; they also possessed inadequate knowledge of necessary concepts and symbols, insufficient mastery of basic facts and incorrect procedures in applying mathematical techniques. As a result, they could not solve problems in Data Handling. Several students could not bring meaning to the problems and did not know in what way to plan and implement Data Handling strategies. Students could not distinguish between relevant and irrelevant data in a mathematical problem and also were not able to categorize them in a table.

\subsection{Students' learning difficulties in evaluating}

Evaluating emphasizes the process of presenting and defending thoughts by making judgment about information, quality of work based on a set of criteria, or validity of ideas. Generally, evaluating focusses on students' ability to judge the value of a subject for a given purpose. In order to find answers on Data Handling problems, the students had to use and integrate all their mathematical knowledge and skills and this task was quite challenging for them. From the interview, most of the primary school students could not decide which method was the best way to solve a given problem on Data Handling. They were also unable to provide a table or graph as the students thinking skills were limited to the ability to memorize and to recall without understanding the functions of each graph.

S11: "I could not remember what I learnt and transform the information concerned into a meaningful mathematical sentence, table or graph in order to answer the problem on Data Handling."

S12: "I do not know which graph to use to solve the questions on Data Handling."

T4 : "Students usually presents the data in a wrong method. They fail to present and defend their works on Data Handling." 
Figure 7 shows a sample of student's work on mathematics exercise sheets in evaluating. The student understood the functions of scales and the way to calculate the scale in Data Handling. However, the student failed to transform the information from the table to the vertical bar graph correctly. In addition, the student also did not calculate the total amount given. As a result, the student presented and defended the data in a wrong way. Besides, most primary school students are lacking of visual-spatial skill, a critical skill in building a connection between problem and diagram. Reference [12] stated lack of visual-spatial skill might cause difficulties in differentiating, connecting and organisng information meaningfully.

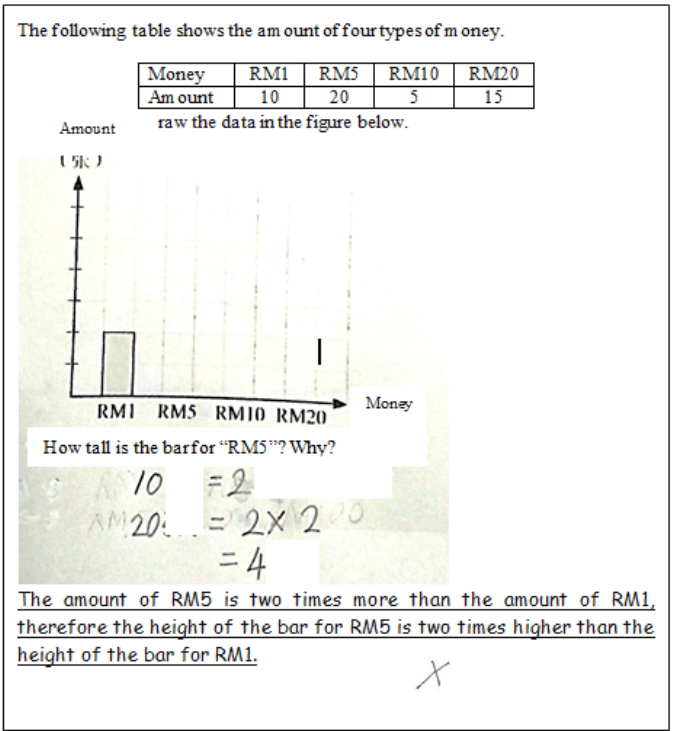

Fig. 7. Asample of student's work on mathematics exercise sheets in evaluating

\subsection{Students' learning difficulties in creating}

Creating involves the process of collecting information from various elements by joining elements in a new meaning or offering alternative solutions. Creating emphasizes on students' creative behavior and actions, with main stress on the formulation of new structures or patterns. Solving and creating a Data Handling mathematical problem focusses on students' creative behavior and actions. It is a time taking task. The students needed to collect data from various elements, devise a procedure to record the data, organise and interpret data as well as create a graph. Thus, by the time they collected and recorded the data they were already bored and were unable to organise and interpret the data. As a result, they lost concentration to study the similar question again. Students would misunderstand the problem in Data Handling and made careless mistakes.

T4 : "Students always makes mistakes due to carelessness to create a graph."

S13: "It involves a lot of steps to create graph. It is easily for me to make mistakes. I do not have time to check my answers." 
Figure 8 shows a sample of student's work on mathematics exercise sheets in creating. The student spent a lot of time to create the graph and thus he did not have enough time to check his work. As a result, he gave incorrect answer. The graph created by the student was a histogram, not a vertical bar statistic graph as it did not have gaps. Besides, the scale used for the pocket money per week was wrong as well as the calculation of pocket money per week for Jian Hong and Xiao Hui were also incorrect.

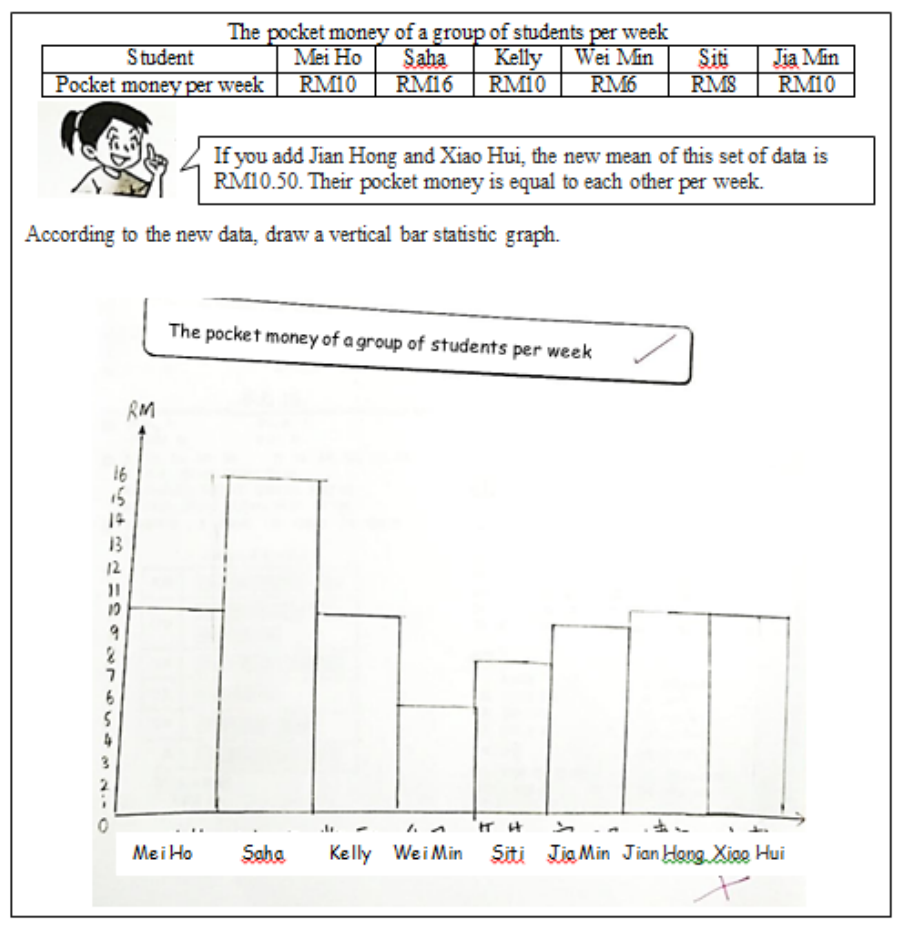

Fig. 8. A sample of student's work on mathematics exercise sheets in creating

Besides, the results indicated that many primary school students had difficulties in giving attention in class. Students' had short concentration span when they were asked to perform a particular task. Therefore, they were not able to solve the problem on Data Handling. Excerpts for interview with a student and a teacher are listed below:

T3 : "Students showed uninterested face when asked to create graph. Many students did not complete Data Handling questions involving creating graphs."

S14:"It is boring to create a graph. It involves a lot of procedures and it is time consuming."

Concentration is more than giving attention [38]. It is the ability to meaningfully focus on a certain task in certain duration of time with the force of intrinsic motivation. Therefore, most of the students felt frustrated and did not complete the whole process of solving Data Handling problems. Table 1 shows the summary of findings from the interview and document analysis on students' learning difficulties at each level of the HOTS cognitive domain in Data Handling. 
Table 1. Findings from the interview and document analysis on students' learning difficulties at each level of the HOTS cognitive domain in Data Handling

\begin{tabular}{|c|c|}
\hline $\begin{array}{l}\text { HOTS Cognitive } \\
\text { Domain }\end{array}$ & Students' Learning Difficulties \\
\hline Applying & $\begin{array}{l}\text { - Confused with the question. } \\
\text { - Did not know what concept to use and how to answer the questions. } \\
\text { - Had difficulties understanding the needs of the questions. They spent a lot of time to } \\
\text { understand the problem. } \\
\text { - Failed to collect and record data. } \\
\text { - Could not construct graphs from the data given. }\end{array}$ \\
\hline Analysing & $\begin{array}{l}\text { - Often make errors while dealing with the facts in the question. } \\
\text { - Did not know which fact to use first, unsure how to make connection, which fact and } \\
\text { formula to use. } \\
\text { - Confused on the way to solve the problems. }\end{array}$ \\
\hline Evaluating & $\begin{array}{l}\text { - Presented the data in a wrong method. } \\
\text { - Failed to present and defend their works systematically. }\end{array}$ \\
\hline Creating & $\begin{array}{l}\text { - Could not concentrate and uninterested in making table or graph. } \\
\text { - Lack of time to solve the questions and create table or graph. } \\
\text { - Always make mistakes due to carelessness when making tables or graphs. }\end{array}$ \\
\hline
\end{tabular}

\section{$4 \quad$ Studies on smart board}

Smart board is more than a screen, a projector, or a computer [22]. It combines all the functions of computer, whiteboard, and projector into a particular system [13]. Smart board can be used to carry out lessons in visual, auditory, and tactile learning [3]. The use of smart boards in the school makes students feel much more relax and happy in learning mathematics as it sounds more interesting and fun. Students' interest could be increase and learning could be facilitate with smart board as a learning tool [4]. Students who learn mathematics using smart board have advanced creativity levels, because smart board facilitates the mathematical learning process [28]. Students also could remember and understand mathematical information better with the help of visual representation on the smart board. Students' mathematics academic archievement improved simultaneously their attitude towards mathematics turned to be more positive. Besides, students' motivation to learn increased with the use of software and media for instance cartoon characters on smart board [5]. In mathematics class, smart board supports students to contribute more in student group discussions, supports them to express their ideas better, allows them to stay on task better and to be more creative [20]. Rather than just getting information in a lecture format, students are actively involved in building their own knowledge [34]. Student's conceptual knowledge gain deeper and can apply that useful information in novel situations. When student build their own knowledge, they are mastering more advanced thinking skills. Students' understanding of present topics is developed to support practical thinking and critical thinking skills [31]. Knowledge gained through higher order thinking processes is easily transferable; student with deep conceptual understanding of an idea are more likely to be able to apply that knowledge to resolve novel problems. Reference [17] proposes that the 
integration of the practice of students' skills with the interactivity of smart board stimulates students' HOTS. By integrating the use of smart board, student models, shares and demonstrates what they have learned, thus, play the role of an instructor. Smart board does not only foster an environment which lets every student to go beyond the surface and dig deeper into a concept but also foster HOTS and differentiated learning. The development of smart board offers various chances for innovative teaching through the use of computer resources and effective approaches to support the teaching learning process and individualized learning [9]. Therefore, with the use of smart board, the level of potential HOTS development among students can be discovered and achieved.

\subsection{The use of smart board to overcome students' learning difficulties in applying}

In applying, students need to carry out or use a procedure in a given situation [1]. When the concept of period is fixed, students remember $10 \%$ of what they read, $20 \%$ of what they hear, $30 \%$ of what they see, $50 \%$ of both what they see and hear, $70 \%$ of what they say, and $90 \%$ of both what they say and do [6]. Hence, the rate of recall is increased when many senses are used in an educational activity, the more the event of learning is permanent. It is significant to form the classroom base on the process of teaching by living and doing so that the students could remember what they had learned in school. Smart board performances as a multimodal portal, gives teachers the potential to use moving or still images and sound to deliver the lesson. The use of audio and video, manipulating and writing text, hiding and revealing, handwriting recognition, retrieving, saving, capturing and manipulating web content, printing notes, shading, animation, and coloring using smart board make classroom lessons fun and visual. Smart board can address the needs of students who find text difficult as the only mode of communication [36]. Smart board can make the lesson enjoyable and ultimately achieve permanent learning [2]. In addition, smart board assists students to understand the needs of the question and feel that they own their learning process. They will understand that their body has a way of learning and their fingers are useful for writing. Smart board helps them discover their own world. It makes it possible to use pictures and words simultaneously. The ability to include visual references is excellent for students in communicating effectively. Moreover, smart board can be updated quickly and easily. Research, real time internet sites, and informational text can be easily incorporated and retrieved during lessons [37]. It helps student to apply appropriate solution to a familiar or an unfamiliar task. Smart board is seen as an important piece of the classroom of the future [27]. Subsequently, teachers should prepare proper learning environments and involve students in interactive learning using smart board as it can help them to get ready for their future.

\subsection{The use of smart board to overcome students' learning difficulties in analysing}

In analysing, students need to break materials into constituent parts and determine how the parts relate to one another and to an overall structure or purpose [1]. Students 
often make errors while dealing with the facts in the questions. With the help of smart board, common misconceptions or error done by students can be immediately recognized and undoing to correct them as the usage of smart board is ensured by different software installed in the computer. Smart board shows information that can be manipulated and displayed with boundless capabilities. It helps students to differentiate important from unimportant parts or relevant from irrelevant parts of existing materials, define in what way the elements fit or function within a structure and conclude whether a point of view is bias, valuable, or any intention underlying existing materials. Besides, smart board assists instructors in schooling with more focus and explaining subjects [41]. Smart board speaks to the multiple senses of sight, sound and touch which helps reinforce topics, create a compelling focal point in the classroom as well as provide extra context for lessons and discussions. Teachers can use smart board to bring up diagrams or images during a lesson and thus offer extra reference materials. In the meantime, students can see strong patterns of their data using smart board and this can help them to make strong claims about their inquiry [15].

\subsection{The use of smart board to overcome students' learning difficulties in evaluating}

In evaluating, students need to make judgment based on criteria and standards. Students need to detect inconsistencies or fallacies within a process or product; determine whether a product has external consistency; detect the appropriateness of a procedure for a given problem [1]. Brainstorming and discussion help students to develop creative solutions and thoughts to a problem. Brainstorming in the classroom can be enjoyable with smart board. Instead of putting the text or ideas together, students can also put various images, diagrams or videos together during their discussion. Smart board can maximize collaboration and facilitate clear communication during students' discussion. By manipulating information on a smart board to answer questions, several students with behavioral and mental challenges who struggle with expressive communication in the class will be given different opportunities for sharing their knowledge. Some teachers use smart board to view videos which represent social circumstances. Smart board offers students with the opportunity to view and analyse social interactions in order to learn and practice suitable answers or judgments. Reference [7] demanded that the advantage of smart board is that teacher in school can save comment and explanation on the smart board, consequently record the lesson for future use by student who absent due to sickness or nonattendance.

\subsection{The use of smart board to overcome students' learning difficulties in creating}

In creating, students need to put elements together to form coherent or functional whole and reorganise elements into a new pattern or structure [1]. Students need to come up with alternative hypotheses based on criteria, devise a procedure for accomplishing some tasks or invent a product. Creating a table or graph by drawing is time consuming; students may make mistakes due to carelessness when making table or 
graph. The main contribution of smart board is that students have the ranges on several topics, to develop their own knowledge, increase the efficiency of learning at any places and contribute to it, contribute to understanding the material, organisng information, self-efficacy in carrying out assignments in a friendly environment, as well as to the representation of products that generate a sense of success, pleasure, and contribute to a more creative and higher standard learning product [8]. Smart board also allows understanding of various topics more quickly and easily, avoiding time consumption because smart board could makes the drawing and writing more comprehensible. It enables the use of various kinds of visuals in computer environment as teaching and learning tools, and make the topics much more easier, more fun and interesting to student as compared to traditional teaching methods. All forms of media such as maps, graphs, videos, photographs, illustrations and games can be used on the smart board, making it incredibly dynamic in nature. This expands the range of content that students can use for presenting information. For students of the digital age, whose lives outside the classrooms are inundated with technology, having smart boards in classrooms provide continuity with their real lives experiences. Their need for instant answers and desire for stimulating, media-rich environment can be satisfied in the colorful displays, huge, touch control and sound capabilities that most smart board provides. As a venue for content, the smart board allows digital learners the immediacy they desire and the ability to find, synthesize, create, share, organise and play with information in exciting and novel ways.

\section{Conclusion}

To put in a nutshell, evidence from interview sessions with the teachers and students as well as document analysis of the students' mathematics exercise sheets showed that primary school students faced various difficulties at each level of HOTS while learning Data Handling as majority of the teachers only used "chalk and talk" method in class, used one way communication, practiced teacher centered learning and did not organise discussion among students. Data Handling is an important topic as it lets students to make sense of information, to detect trends and patterns as well as to forecast and plan for the future [16]. It should be mastered by every student when they are in primary schools. However, the "chalk and talk" method led to limited student thinking since students were just passive listeners. As students are active learners, teachers in schools should provide opportunities for students to think critically about Mathematical content through a range of activities. This method will help to prepare them for the challenges in their daily lives. Smart boards are recognised to have a positive influence on students' achievement and attitude. A study showed that it facilitated students to visualise mathematics, verify conjectures, involve in active learning strategies, insist positive attitudes, and build confidence in their ability to do mathematics [19][42]. Thus the use of smart board creates rich interaction among students, under relatively unsupervised conditions. In conclusion, learning strategies, methods or programs which are meaningful and interesting such as using smart board should be integrated into students' learning 
in order to enhance HOTS in Data Handling among primary school students in Malaysia.

\section{$6 \quad$ References}

[1] Anderson, L., and Krathwohl, D. (2001). A Taxonomy for Learning, Teaching, and Assessing: A Revision of Bloom's Taxonomy of Educational Objectives. Longman Publishing Co., New York, New York.

[2] Aktas, S., and Aydin, A. (2016). The effect of the smart board usage in science and technology lessons. Eurasian Journal of Educational Research, 64, 125-138 https://doi.org/10.14689/ejer.2016.64.7

[3] Beeland, W. (2001). Student engagement, visual learning and technology: Can interactive whiteboards help?, Paper presented at Annual Conference of the As-sociation of Information Technology for Teaching Education, Trinity College, Dublin.

[4] Berna Tataroglu and Ayten Erduran. (2010). Examining students' attitudes and views towards usage an interactive whiteboard in mathematics lessons. Procedia - Social and Behavioural Sciences, 2(2), 2533-2538. Retrieved from https://doi.org/10.1016/j.sbspro.2010. $\underline{03.368}$

[5] Burcu Turan (2014). Smart board in Mathematics Education, The Use of Cartoon Characters Impact on Student Success, Near East University, Department of Computer Education and Instructional Technology, North Nicosia, Cyprus.

[6] Cilenti, K. (1991). Egitim teknolojisi ve ogretim [Educational technology and education]. Ankara: Kadioglu Matbaasi.

[7] [7]Clark, D. (2012). Smart board or souped-up blackboard? Retrieved December 15, 2015, from http://donaldclarkplanb.blogspot.co.uk/2012/10/interactive-whiteboard-or-soupedup.html.

[8] Dori, S., and Kurtz, G. (2015). Student's perceptions meaningful learning via ICT. Paper presented at the 2015 Chais Annual Meeting, Open University, Raa-nana.

[9] Fonseca LMM. (2013). Development of a learning object for caring for the senso-ry environment in a neonatal unit: noise, light and handling. J Nurs Educ Pract. 3(2), 11-18.

[10] Franklin, C., Kader, G., Mewborn, D. S., Moreno, J., Peck, R., Perry, M., and Scheaffer, R. (2005). A curriculum framework for K-12 statistics education. GAISE report. American Statistical Association. Retrieved from http://www.amstat.org/education/gaise/.

[11] Gal, I. (2002). Adult's statistical literacy. Meanings, components, responsibili-ties. International Statistical Review, 70(1), 1-25. https://doi.org/10.1111/j.1751-5823.2002.tb00336.x

[12] Garderen, D.V. (2006). Spatial Visualization, Visual Imaginary and Mathemati-cal Problem Solving of Students with Varying Abilities. Journal of Learning Disabilities 39(6): 496506. https://doi.org/10.1177/00222194060390060201

[13] Giles, R.M., and Shaw, E.L. (2011). SMART Boards rock. Science and Chil-dren.

[14] Glanville, J.L. and Wildhagen, T. (2007). The measurement of school engage-ment: Assessing dimensionality and measurement invariance across race and eth-nicity. Educational and Psychological Measurement, 67, 1019-1041. https://doi.org/10.1177/0013164406 299126

[15] [15]Goettler E. (2009). SMARTboard: The SMART Way To Engage Students. Re-trieved from https://ed.psu.edu/pds/teacher-inquiry/2009/goettlere.pdf.

[16] Griffiths, R. (2001). What's your favourite data? Data Handling Activi-ties. Lower Numeracy, 21(4), 34-35. 
[17] Jones, P., Kervin, L., and McIntosh, S. (2011). The interactive whiteboard: Tool and/or agent of semiotic mediation. Australian Journal of Language and Literacy, 34(1), 38-60. Retrieved from http://www.akea.edu.au/resources/AJU.

[18] Kazima, M and Adler, J. (2008). Mathematics for teaching: Observations from two case studies South Africa Journal of Education: Vol. 28: 283-299.

[19] Kersaint, G. (2007). Toward technology integration in mathematics education: A technology integration course planning assignment. Contemporary Issues in Technology and Teacher Education, 7(4), 256-278.

[20] Khamis Mousa Nejem and Wafa Muhanna. (2014). The Effect of Using Smart board on Mathematics Achievement and Retention of Seventh Grade Students. International Journal of Education, 6(4), 107. https://doi.org/10.5296/ije.v6i4.6753

[21] L. Dee Fardanesh, H. (2010). A Classification of Constructivist Instructional Design Models Based on Learning and Teaching Approaches. Online Submis-sion, 16. Retrieved from http://www.ed.utah.edu/users/robert.zheng/6750reading/fardanesh.pdf.

[22] Levy, P., and Partnership, S. E. i. C. (2002). Interactive whiteboards in learning and teaching in two Sheffield schools: a developmental study: Sheffield Excel-lence in Cities Partnership.

[23] [23]Malaysia Ministry of Education. (2004) Annual Report Ministry of Education 2004, Putrajaya: Ministry of Education Malaysia.

[24] [24]Malaysia Ministry of Education. (2012). KSSR Mathematik DSKP Tahun 1. Retrieved from https://drive.google.com/file/d/0B7Nqkj9J60ucTUVGeE5YdHJyMTg/view.

[25] [25]Malaysia Ministry of Education. (2012). Malaysia Education Blueprint 2013-2025: Preliminary report. Retrieved from http://www.moe.gov.my/userfiles/file/PPP/PreliminaryBlueprint-Eng.pdf.

[26] Marks, H. M. (2000). Student engagement in instructional activity: Patterns in elementary, middle, and high school years. American Educational Research Jour-nal, 37 (1), 153-184. https://doi.org/10.3102/00028312037001153

[27] Minor, B., Bracken, M., Geisel, P., and Unger, S. (2006). SMART Boards in the classroom: The influence of interactive boards in Education. Retrieved Sep-tember 22, 2014, from http:/tiger.towson.edu/users/sunger2/smart boards in the classroom.htm.

[28] Mohammad-Hassan Behzadi and Maryam Manuchehri. (2013). Examining Crea-tivity of Students through Smart board in Learning Mathematics. Mathematics Education Trends and Research, 2013, 1-7. https://doi.org/10.5899/2013/metr-00008

[29] Montague-Smith, A., Price, A.J. (2012). Mathematics in Early Years Educa-tion [3rd ed.]. New York: Routledge.

[30] OECD. (2013). PISA 2015 Draft Collaborative Problem Solving Framework March 2013. OECD (p. 89).

[31] Ozusağlam, E. (2007). Web-based mathematics education and courses example of presentation. Pamukkale University Faculty of Education Journal, Vol.21, 33-43.

[32] Painter, D. D., Whiting, E., and Wolters, B. (2005). The use of an interactive whiteboard in promoting i n t e r a c t i v e teaching and learning. VSTE Journal, 19(2), 31-40.

[33] Reys, R. E., Lindquist, M. M., Lambdin, D. V., Smith, N. L., Rogers, A., Falle, J., Frid, S., and Bennett, S. (2012). Helping Children Learn Mathemat-ics [1st ed.]. Milton. QLD: John Wiley and Sons Australia, Ltd.

[34] [34]SMART Technologies. (2007). Highland Village Elementary School, Lewisville Independent School District: Flower Mound, Texas. SMART Technologies Case Study Report.

[35] Smith, F., Hardman, F., and Higgins, S. (2006). The impact of interactive whiteboards on teacher-pupil interaction in the national literacyandnumeracy strategies. British Educational Research Journal, 32(3), 437-451. https://doi.org/10.1080/01411920600635452 
[36] Somekh, B., Haldane, M., Jones, K., Lewin, C., Steadman, S., Scrimshaw, P., et al., (2007). Evaluation of the Primary Schools Whiteboard Expansion Project: Report to the Department for Children, Schools and Families. Centre for ICT, Pedagogy and Learning Education and Social Research Institute, Manchester Metropolitan University. Retrieved on December 29, 2008, from http://partners.becta.org.uk/upload- dir/downloads/page_documents/research/whiteboards_expansion_summary.pdf.

[37] Starkman, N. (2006). The wonders of interactive whiteboards: No cutting-edge classroom is complete without one. T H E Journal, 33(10), 36-39.

[38] Stendall, R. (2009). Use Your Six Intellectual Factors to Achieve Anything in Your Life. Article-idea. Retrieved from http://www.article-idea.com/profile/raystendall-.

[39] TIMSS. (2011), Trends in international mathematics and science study, Interna-tional Associations for the Evaluation of Educational achievement, Retrieved from http://timss.bc.edu/timss2011/.

[40] Vygotsky, L. S. (1978). Mind in society: The development of higher psycholog-ical processes (M. Cole, V John-Steiner, S. Scribner, and E. Souberman, Eds.). Cambridge, MA: Harvard University Press.

[41] Wong, KT, Goh, P.S.C. and Osman, R. (2013). Affordances of Interactive Whiteboards And Associated Pedagogical Practices: Perspectives Of Teachers of Science With Children Aged Five To Six Years.TOJET: The Turkish Online Journal of Educational Technology 12(1): $1-8$

[42] Abdullah, A.H. and Zakaria, E. (2013). The effects of van hiele's phase-based instruction using the geometer's sketchpad (GSP) on students' levels of geometric thinking. Research Journal of Applied Sciences, Engineering and Technology 5(5): 1652-1660 https://doi.org/10.19026/rjaset.5.4919

\section{$7 \quad$ Authors}

Elizabeth Julius is with Kebbi State University of Science and Technology Aliero, Kebbi State, Nigeria.

Soh Hon Mun, Abdul Halim Abdullah, Mahani Mokhtar, and Nornazira Suhairom are wirth Universiti Teknologi Malaysia, Johor Bahru, Malaysia.

Article submitted 23 September 2018. Resubmitted 16 October 2018. Final acceptance 26 October 20187. Final version published as submitted by the authors. 